\title{
Enhancing literacy and curriculum using digitalized collections and approaches
}

\author{
Bill Lukenbill \\ University of Texas at Austin, UTA 5.442 - D8600, Austin, Texas 78701-1213, USA
}

\begin{abstract}
Digitized collections offer a wealth of resources for improving a wide variety of literacies that promote critical thinking skills, instruction and curriculum enhancements. Digitized collections and processes are increasing rapidly in their development and availability and as such introduce issues such as public access, copyright laws, limitations on use, and the integration of both free and commercially available digitalized materials.

Governments around the world offer an abundance of digitalized information, often with curriculum guidance. Together with these issues, questions concerning how to evaluate and integrate curriculum and literacy ideas into instruction using digitalization are considered. This paper provides examples of subject areas attuned to digitations including literature, history, current events, sociology, health and science, and local collections. Suitable policies and procedures are discussed promoting efficient programming including collection development, project management, technical needs, online dissemination, and reference and consultation services.
\end{abstract}

\section{Introduction}

Digitalized collections and processes are increasing rapidly in their development and availability. These rapid changes encourage and require us to consider diversified meanings of literacy and how digitalization interacts in concert with these meanings. The widespread availability of digitalization affects our perception of the world and our attitudes and beliefs about the world as a community.

\section{Evidenced-based learning}

Can evidence-based research support the claim that electronic learning facilitates literacy? Evidence-based learning centers on hard evidence showing the effectiveness of instruction. If so, evidence-based learning may free us from older theories and practices about how students learn and allow us to look at learning and the methods of learning in new ways (Thalheimer, n.d.).

\section{What is digitalization? What is Web 2.0?}

Digitization is the process of converting analog information into digital format. The materials to be converted can include letters, manuscripts, books, photographs, maps, audio recordings, microforms, motion pictures and ephemera. Three-dimensional objects can also be digitized. The goal of digitization is to improve access to the materials and to preserve materials for future use. To that end, most digitized materials become searchable via the Internet and other forms of electronic media.

Conversion into digital format requires devices that can transform analog signals into digitalized singles. Typically this is done by, scanning, digital photography, digital recording, audio, video and new forms of medical imaging. It is important that the information be true to the original.

With the advent of Web 2.0, schools now have many ways of making digitalization products and instruction available to students.

\section{Literacy and digitalization across the curriculum}

Tools exist for a wide range of digitalization methods that allow integration into literacy instruction; but we must consider the expanding nature of literacy. The following are just a few examples of now literacy permeates the curriculum:

(C) 2010 IASL, SLAQ and therein by the authors. Diversity Challenge Resilience: School Libraries in Action Proceedings of the $12^{\text {th }}$ Biennial School Library Association of Queensland, the $39^{\text {th }}$ International Association of School Librarianship Annual Conference incorporating the $14^{\text {th }}$ International Forum on Research in School Librarianship, Brisbane QLD Australia, 27 September - 1 October 2010. 
- Reading and writing literacy.

- Cultural literacy.

- Art literacy.

- Science literacy.

- Health literacy.

- Visual literacy.

\section{Access to electronic collections}

Copyright and intellectual property rights

We must always be aware that copyright and intellectual property rights are fundamental to developing digitalized products. Laws in each country vary so it is not possible here to provide specific examples of copyright laws; but most countries protect the right of creators to control the distribution of their intellectual works.

\section{Students' rights to copyright protection}

In terms of student created products as a classroom exercise, we ask the question: Who among these holds the copyright, the student or the school? Broadly speaking, U. S. Copyright law and others such as the United Kingdom and the European Union give copyright to anyone who creates an intellectual work. In some circumstances, the work belongs to the corporate body if the work is done as an expected work responsibility. If schools wish to hold exclusive rights, a policy should be established that states that the school wishes to hold rights to the products created by students, and students are allowed to sign a waiver to their copyrights if they agree. In some situation, under legal counsel, the school may require that students surrender their copyrights (Russell, 2009).

\section{Acceptable use standards and policies}

Within school environments, certain norms of behavior and attitudes of respect are expected. This is certainly true of the use and production of digitalized materials, programs, and exhibits. Acceptable use policy (AUP) is one method of ensuring that behavior expectations are met. "AUP is a written agreement, signed by students, their parents, and teachers outlining the terms and condition of Internet use" (Crane, 2009, p. 3) and expectations for student-produced digitalized resources.

\section{Culture differences and respect}

Many of us live in multicultural nations with varied cultural and social identities. This means that while encouraging students to produce and distribute digitalized products, we must also help them understand and respect differing cultural and social norms. These include gender roles, religious and national symbols and sensitive social issues. Narratives as well as pictorial displays must be considered in terms of cultural differences and respect (International Council of Museums/Conseil International des Musées, 2006).

\section{Filtering censorship and government controls}

Access to the Internet is not always easy. Most governments filter through laws and other restrictive practices. We can argue that these laws interfere with the students' rights and needs for information found on the Internet and information available on commercial databases. I will use the United States as an example of filtering. Most American states and the federal government have passed filtering laws in order to protect students from harmful content that they might encounter on the Internet. Filtering programs often use keywords to screen and prevent information from being posted. For example, many terms associated with human anatomy and personal lives are automatically filtered. Legitimate information is then barred although it may contain scientific and/or academically accepted information.

Sutton (2005, p. 803) found in her dissertation study of high school students who used the Internet to research

(C) 2010 IASL, SLAQ and therein by the authors. Diversity Challenge Resilience: School Libraries in Action Proceedings of the $12^{\text {th }}$ Biennial School Library Association of Queensland, the $39^{\text {th }}$ International Association of School Librarianship Annual Conference incorporating the $14^{\text {th }}$ International Forum on Research in School Librarianship, Brisbane QLD Australia, 27 September - 1 October 2010. 
assigned term papers that students' Internet inquiries were often blocked by filtering programs from obtaining legitimate, constitutionally-protected information.

\section{Examples of school-based digital activities}

Web 2.0 and its assortment of interactive technologies and tools allow teachers, teacher-librarians, and students to expand their creativeness and explore ways to provide and experience literacy in all of its varied meanings and manifestations. Correct applications and use of Web 2.0 tools promotes critical thinking skills, a fundamental part of literacy (Crane, 2009, p.5-8).

Through project-based learning, students can be encouraged to consider real world problems by observing, gathering information, and proposing solutions. Similarly, literacy can be encouraged through inquiry-based learning. Inquiry learning offers students the opportunity to ponder information and what it means in different contextual settings and to problem-solve within a variety of multidisciplinary areas (Crane, 2009, pp. 5-8).

\section{Some concrete examples \\ Blogs}

Blogs are shared online journals where people can post diary entries with updates about their personal experiences and hobbies. In the case of students, blogs can be used to post summaries and information and ideas learned from assignments, and to interact in book discussions with their peers. Blogs are generally posted by date; and bloggers encourage immediate feedback and comments from readers. Students who manage the blog can encourage others to post such items as texts, images, audio and video. Blogs used in a classroom setting create a "community of learners" (Crane, 2009, pp.18-21). Blogs can be used in classes such as literature, history, the sciences, and other subject areas, as blogs encourage outside discussions and comments (Crane, 2009, pp. 20-22).

E-scrapbooking is a site that presents examples of how teachers can create and use blogs in a variety of subjects (Lamb \& Johnson, 2006). Listings include examples of how to use the graphic novel as a means of teaching various subjects.

\section{Podcasts}

A useful definition of podcasts is that it is "a digital recording of a radio broadcast or similar program, made available on the Internet for downloading to a personal audio player," ... [Now] expanded to include video as well as audio" (Glossary, 2010). Podcasts can be created by students and broadcast to other students anywhere in the world. A list of school examples is available at $\mathrm{K}-12$ Handhelds. These examples include mathematics, physical education, poetry, digitalization projects, book reviews, information skills, and biology.

\section{Wikis}

A wiki site may allow anyone to edit, delete, or modify the content of a collection of information (Tech Glossary, 2010) or the wiki may be proprietary and only editable by the creator/s. A well-known example of an open wiki that anyone can edit is Wikipedia. Some instructional wikis offers students opportunities to reflect on issues and comment on what other people have said about an issue. For example, students can propose an idea and then open that idea up for discussion (Crane, 2009, p. 65). Other instructional wikis might be open only by invitation from the creator.

\section{Google}

Google, of course, is a popular search engine for finding resources on the World Wide Web (WWW). It is based on finding keywords embedded in Web pages throughout the WWW. Google provides a wide-range of applications such as Apps [Applications], Alerts, Documents, Groups, Earth, Notebook, Reader, Graphic Organizer, and a section for educators (Google resources; Crane, 2009, p 110).

(C) 2010 IASL, SLAQ and therein by the authors. Diversity Challenge Resilience: School Libraries in Action Proceedings of the $12^{\text {th }}$ Biennial School Library Association of Queensland, the $39^{\text {th }}$ International Association of School Librarianship Annual Conference incorporating the $14^{\text {th }}$ International Forum on Research in School Librarianship, Brisbane QLD Australia, 27 September - 1 October 2010. 
These applications can be used in a variety of subjects such as the social sciences, literature, writing, biology, economics, political science, journalism and current events. For example, Google Earth can be used for researching selected topics which can be mapped, such as Cuba. Information about the topic can then be drawn from appropriate URLs as well as tracked through Google News Alert. Comments and reactions to this information can also be recorded using Google Notebook. Finally when all the information is assembled and synthesized, a PowerPoint presentation can be developed and presented (Crane, 2009, pp. 109-129).

\section{Creating web sites}

Many schools have made good use of web sites for both instructional as well as information provisions.

Dreamweaver is an Adobe program that is widely used by educators to create high-end web sites. It may be too complex and costly for the casual user. Other programs may serve the novice better. For example, Weebly or Google Sites might be considered. Another type of wiki design program is PBWorks in Educators. This program:

[L]ets you create a secure online workspace in about 60 seconds. Encourage classroom participation with interactive wiki pages that students can view and edit from any computer. Share class resources and completed student work with parents. You can even collaborate with fellow educators on courses and curriculum and manage the work of running your school or district (PB Works).

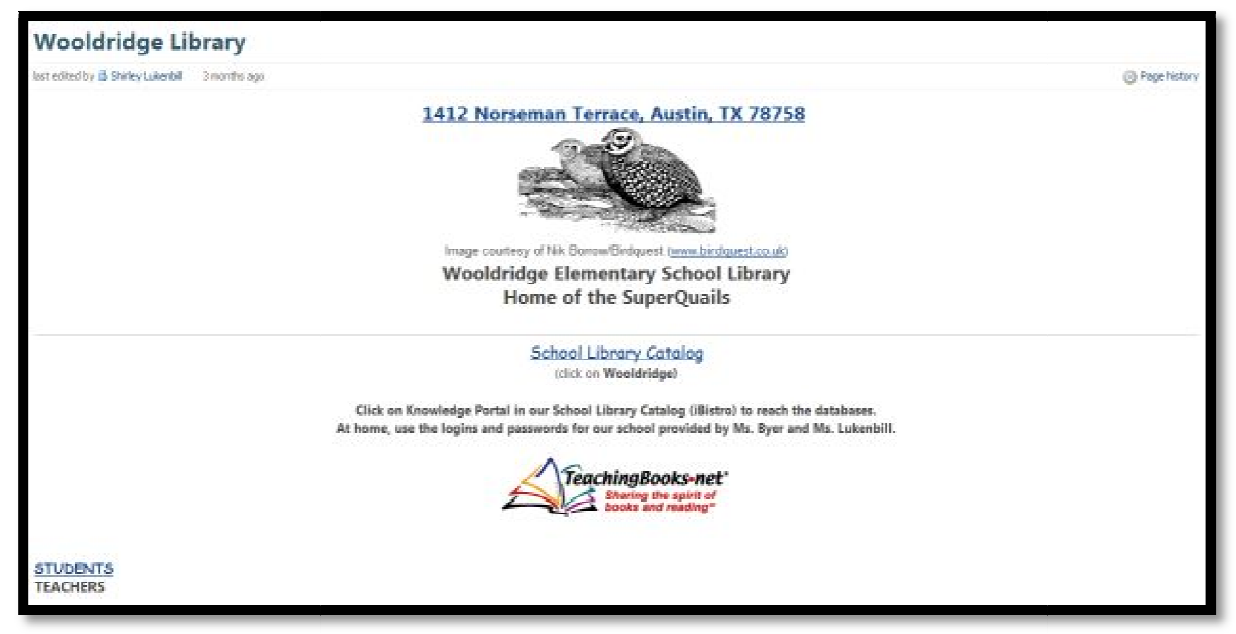

Figure 1.1 following is an example is a wiki created using PBWorks for Educators. Published by permission.

\section{Voice Thread}

Ed.VoiceThread, part of VoiceThread, is: a "communications network for K-12 students and educators" (Voicethread, 2007-2010). Teachers and students can create and work together "on digital stories and documentaries, practicing and documenting language skills, exploring geography and culture, solving math problems, or simply finding and honing student voices." It is excellent for multicultural and foreign language instruction (Crane, 2009, pp. 134-150).

\section{Social networking in education}

Wikipedia describes social networking as "a social structure made of individuals (or organizations) called 'nodes,' which are tied (connected) by one or more specific types of interdependency, such as friendship, kinship, ... beliefs, knowledge or prestige" (Wikipedia, March 4, 2010). Schools can use social networking

(C) 2010 IASL, SLAQ and therein by the authors. Diversity Challenge Resilience: School Libraries in Action Proceedings of the $12^{\text {th }}$ Biennial School Library Association of Queensland, the $39^{\text {th }}$ International Association of School Librarianship Annual Conference incorporating the $14^{\text {th }}$ International Forum on Research in School Librarianship, Brisbane QLD Australia, 27 September - 1 October 2010. 
well, but there are precautions that must be observed such as ensuring inappropriate behavior will not occur: ("Kim Klein : Weblog..."). Klein suggests that those who are pondering social networking as an instructional tool consider Ning and Imbee (Ning; Imbee).

\section{The classroom and digitalization throughout the curriculum}

Digitalization is applicable throughout the curriculum using many tools and techniques. To promote the widespread development of digitalized curriculums, commercial companies such as Adobe, Discovery Education, PBS Teachers, and Intel Education provide many detailed, free lesson plans for digitalization teaching using their products. The Adobe lesson plans are extensive and are available at their web site (Digital School Collection Teacher Resources). Some specific topics that lend themselves readily to digitalization include the following areas:

- Art

The Montgomery County Public Schools in Maryland has developed an art curriculum based on digitalization using these Adobe products such as Adobe Photoshop, Adobe Illustrator, Adobe Indesign and Macromedia. "All of the lessons produced in the digital arts lab are intended to expand upon the students' understanding of the production of art as a creative and unique endeavor [sic.]" (Montgomery County Public Schools).

- Local environments

Local environments offer an abundance of ideas for digitalization instructional activities and products. This definition of local history provides evidence of the richness that this topic provides:

Local history is the study of history in a geographically local context and it often concentrates on the local community. It incorporates cultural and social aspects of history (Wikipedia, September 10, 2010).

All local history is unique. School learning zone, a creation of "England's Past for Everyone, Victoria County" (2008) offers many examples that can be adapted to local history studies. These include historic houses and places, architectural features (home, buildings), trails, agriculture and forestry, immigration patterns and historic emblems. Digitalized instructional materials included in these units can include photographs, records such as burial and older church records and maps. Students can also add digitalized products as they explore their local environments. Other topics such as local biography, oral histories of residents of the area, unique flora and fauna, specialized industries, languages and colloquialisms, folklife, folk music, and folk arts and crafts are other examples that offer good instructional and digitalization opportunities.

\section{Exploring existing collections and their support for curriculum and instruction}

The Internet offers an abundance of digitalized information appropriate for students and teachers. The list below is by no means an exhaustive list, but it does show the great variety of sites that offer digitalized information on a many issues. Some of these offer interactive instruction games and lesson plans for teachers. For the most part those listed are not-for-profit sites. A list of these available on request at luke@ischool.utexas.edu.

\section{Reference, consultation and policies}

Like any kind of information resources that are offered, reference and consultation services are required to better facilitate use of digital resources. This definitely includes digitalized resources whether they are locally mounted or available through the Internet. A vast amount of digitalized information exists. This is both good and bad. Good because they are there; bad because they are often hard to find and to evaluate. The teacher-librarian has a responsibility to design and develop sites and portals that are user friendly. Assistance to the user and an accessible help desk is always required. Teacher-librarians must be able to evaluate the products that they mount, as well as those drawn from other sources. Instruction in how to find and navigate the various systems and how to market or promote the availability of these resources is an important part of consultation and reference

(C) 2010 IASL, SLAQ and therein by the authors. Diversity Challenge Resilience: School Libraries in Action Proceedings of the $12^{\text {th }}$ Biennial School Library Association of Queensland, the $39^{\text {th }}$ International Association of School Librarianship Annual Conference incorporating the $14^{\text {th }}$ International Forum on Research in School Librarianship, Brisbane QLD Australia, 27 September - 1 October 2010. 
services.

Collection development policies of digitalized resources must be formulated. Elements in the collection policy can include descriptions of different digital formats, definitions, responsibilities for selection, criteria for selection and review processes, and the scope and formats to be included. In addition to these, a collection policy must reflect knowledge of licensing and use agreements for certain acquired collections, and limitations on use by students and teachers of these resources. Access issues such as filtering, government rules and regulations, school policies, laws, and court rulings must be considered in developing a legally defensible policy. The needs of education and instructional support will play an important role in formulating the policy.

As with any collection development policy, policies must be developed for weeding and maintenance of the digital collection. Retention considerations as to how long a digitalized collection will remain available must be included. Policies need also to include equipment needs and space allocations. A part of the policy must address the issues of staff training directed at creating and maintaining digitalized images, on how to administer the program, and cost considerations.

\section{Production techniques and issues \\ Facsimile production and text scanning}

In its classic sense, facsimile production is copying or reproduction of a book, print, photography, or artifact as true to the original document as possible. This means an accurate presentation of scale, color, text, condition and other qualities. Some say that the gold standard for facsimile production is photography. From there a photographic image can be captured with a variety of scanning techniques (Wikipedia, August 23, 2010). Others maintain that facsimile production can be a scanned document as long as high reproduction standards prevail so that the integrity of the original object is maintained.

Text scanning is commonly used in libraries and offices. The most common use is Optical Character Recognition (OCR) full text scanning and PDF creation and output using word processors such as Microsoft Word. One of the problems here is that OCR programs that come with commercial scanners aimed at the general market are not always powerful enough to capture the complete text. In such cases, a more sophisticated OCR program must be used. The Abby FineReader 10 is such a program. Other digitization equipment useful in developing a wide variety of materials that can help promote literacy includes:

$35 \mathrm{~mm}$ slide and negative scanners

Film scanners $(8 \mathrm{~mm}, 9.5 \mathrm{~mm}, 16 \mathrm{~mm})$

Flatbed scanner for large formats (posters, maps)

Digital cameras and camcorders

Audio and video converters

Artifact converters (3D scanning, imaging, and measurement)

Microscope cameras

These devices are self explanatory by their names and are well described in commercial vendor sources.

\section{Conclusion}

Digitalization in education is used not to celebrate the wonders of electronic technology and the rapid expansions of information. Rather it is promoted solely to meet and satisfy the intellectual and developmental needs of students as they prepare to move into today's complex world. Above all, education within digital frameworks must always be humane, paying close attention to ethnic and personal diversities, cultures, and school environments and expectations that arise there these sources (Study on value orientation of educational resources' digitization, 2010). Digitalization means change not only in how we teach and learn, but how we

(C) 2010 IASL, SLAQ and therein by the authors. Diversity Challenge Resilience: School Libraries in Action Proceedings of the $12^{\text {th }}$ Biennial School Library Association of Queensland, the $39^{\text {th }}$ International Association of School Librarianship Annual Conference incorporating the $14^{\text {th }}$ International Forum on Research in School Librarianship, Brisbane QLD Australia, 27 September - 1 October 2010. 
accommodate change itself. The late John F, Kennedy, Jr. reminded us of this when he said: "Change is the law of life. And those who look only to the past or present are certain to miss the future" (Wisdom quotations).

\section{References}

Crane, Beverly E. (2009). Using web 2.0 tools in the K-12 classroom. New York: Neal-Schuman Inc.

Digital School Collection Teacher Resources. Retrieved February, 14, 2010 from

http://www.adobepolicy.nl/education/instruction/adsc and http://www.adobe.com/ products.

Glossary. (2010). Raytheon BBN Technologies. Retrieved February 12, 2010, from

http://www.bbn.com/utility/glossary/

[Google resources]. Retrieved February, 2010 from http://www.lib.unc.edu/instruct/manuscripts/glossary; http://www.google.com/alerts http://www.google.com/educators/gta.html; http://www.free-seo-

news.com/google-resource-page.htm.

International Council of Museums/Conseil International des Musées. (2006). ICOM code of ethics for museums. Retrieved February, 13, 2010, from http://icom.museum/ethics.html\#section4

K-12 handhelds. Retrieved February, 14, 2009 from http://www.k12handhelds.com/podcastexamples.php.

Kim Klein : Weblog :Why hasn't social networking taken off in K-12 education? Retrieved Febebruary, 3, 2010 from http://community.saugususd.org/jklein/weblog/441.html.

Imbee. Retrieved February, 6, 2010 from http://www.imbee.com.

Lamb, A. \& Johnson, L. (2006). Let's e-scrapbook. Retrieved September 17, 2010, from http://escrapbooking.com/

Montgomery County Public Schools. Retrieved February, 14, 2010 from http://www.montgomeryschoolsmd.org/schools/blakehs/staff/overmanj/lessons.html; http://www.montgomeryschoolsmd.org/schools/blakehs/staff/overmanj/lessons.html.

Ning. Retrieved Feb. 5, 2010 from (http://www.ning.com; from Eduspaces http://eduspaces.net.

PB Works. Retrieved March 5, 2010 from

http://pbworks.com/content/edu+overview?utm_campaign=Three+Boxes\&utm_source=Edu+overview.

Russell, Carrie. (2009, December 1). Who owns students' works? Some appropriate use policies aren't altogether appropriate. School Library Journal. Retrieved February 26, 2009, from

http://www.schoollibraryjournal.com/article/CA6708192.html?industryid=47058

Schools learning zone: Bringing local history to schools. (2008). England's past for everyone. Retrieved March 5, 2010 from http://www.englandspastforeveryone.org.uk/schools/content/interactive-resources

Study on value orientation of educational resources' digitization. (2010). Latest Science @ rticles. Retrieved March 5, 2010 from http://www.latest-science-articles.com/Education_Science/Study-on-Value-Orientation-ofEducational-Resources--Digitization-5438.html).

(C) 2010 IASL, SLAQ and therein by the authors. Diversity Challenge Resilience: School Libraries in Action Proceedings of the $12^{\text {th }}$ Biennial School Library Association of Queensland, the $39^{\text {th }}$ International Association of School Librarianship Annual Conference incorporating the $14^{\text {th }}$ International Forum on Research in School Librarianship, Brisbane QLD Australia, 27 September - 1 October 2010. 
Sutton, L. S. (2005). Experiences of high school students conducting term paper research using filtered Internet access. Ph.D. dissertation: Wayne State University. Abstracted in Dissertation Abstracts International, vol. 66A, no. 3 .

Tech glossary. (2010). LSC Technology Initiatives Grants Program. Retrieved March 1, 2010, from http://tig.lsc.gov/techglossary.php

Thalheimer, W. (n.d.). Will at work learning. Retrieved February 28, 2010, from http://www.willatworklearning.com/2007/07/evidence-.html

Voicethread. (2007-2010). Retrieved March 4, 2010 from http://voicethread.com/products/k12/

Wikipedia. (March 4, 2010). Social network. Retrieved March 4, 2010 from

http://en.wikipedia.org/wiki/Social_network

Wikipedia. (August 23, 2010). Facsimile. Retrieved September 20, 2010 from

http://en.wikipedia.org/wiki/Facsimile

Wikipedia. (September 20, 2010). Local history. Retrieved September 20, 2010 from

http://en.wikipedia.org/wiki/Local_history

Wisdom quotations: quotations to challenge and inspire - Change/growth quotations. Retrieved March 5, 2010 from http://www.wisdomquotes.com/topics/changegrowth/ 